UCRL-TR-202363

\title{
High-Accuracy X-ray Imaging of Meso-scale Targets - Final Report
}

Walter W. Nederbragt

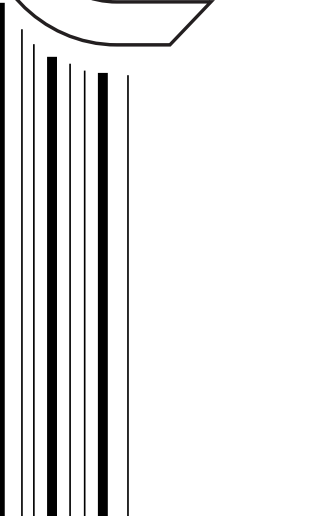




\section{DISCLAIMER}

This document was prepared as an account of work sponsored by an agency of the United States Government. Neither the United States Government nor the University of California nor any of their employees, makes any warranty, express or implied, or assumes any legal liability or responsibility for the accuracy, completeness, or usefulness of any information, apparatus, product, or process disclosed, or represents that its use would not infringe privately owned rights. Reference herein to any specific commercial product, process, or service by trade name, trademark, manufacturer, or otherwise, does not necessarily constitute or imply its endorsement, recommendation, or favoring by the United States Government or the University of California. The views and opinions of authors expressed herein do not necessarily state or reflect those of the United States Government or the University of California, and shall not be used for advertising or product endorsement purposes.

This work was performed under the auspices of the U. S. Department of Energy by the University of California, Lawrence Livermore National Laboratory under Contract No. W-7405-Eng-48.

This report has been reproduced directly from the best available copy.

Available electronically at http://www.doc.gov/bridge

Available for a processing fee to U.S. Department of Energy

And its contractors in paper from

U.S. Department of Energy

Office of Scientific and Technical Information

P.O. Box 62

Oak Ridge, TN 37831-0062

Telephone: (865) 576-8401

Facsimile: (865) 576-5728

E-mail: reports@adonis.osti.gov

Available for the sale to the public from

U.S. Department of Commerce

National Technical Information Service

5285 Port Royal Road

Springfield, VA 22161

Telephone: (800) 553-6847

Facsimile: (703) 605-6900

E-mail: orders@ntis.fedworld.gov

Online ordering: http://www.ntis.gov/ordering.htm

OR

Lawrence Livermore National Laboratory

Technical Information Department's Digital Library

http://www.llnl.gov/tid/Library.html 
High-Accuracy X-ray Imaging of Meso-scale Targets

Final Report

Walter Nederbragt

February 4, 2004 
TABLE OF CONTENTS:

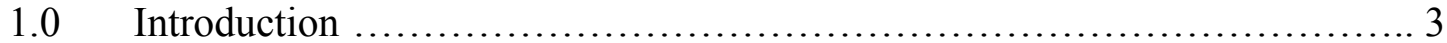

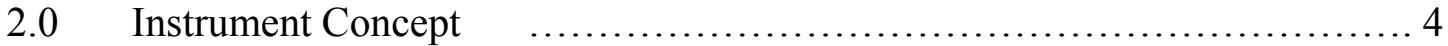

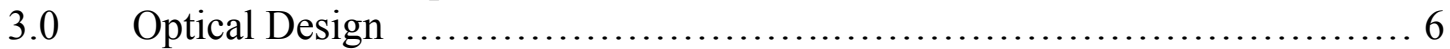

4.0 Mandrel Fabrication $\quad$.

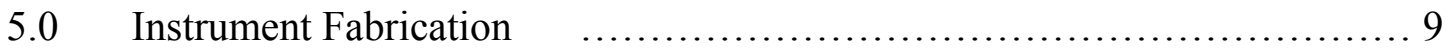

6.0 Optic Fabrication $\quad$..................................................... 11

7.0 Optic Tests ....................................................... 13

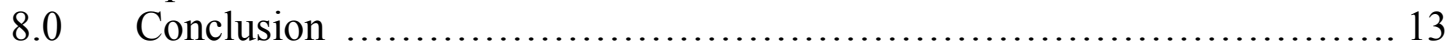

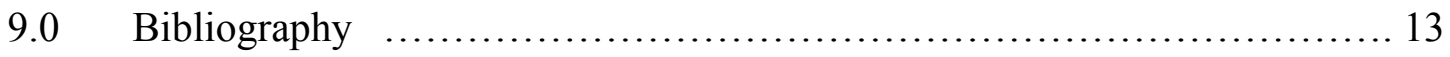




\subsection{Introduction}

Hundreds of target assemblies (see Figure 1.1) will be constructed annually for use on NIF or OMEGA in the near future. Currently, we do not have the capability to tomographically characterize the target assemblies at the desired resolution. Hence, we cannot verify if an assembly has been assembled correctly. The Engineering Directorate, through the LDRD program, provided funding to help solve this problem. This report describes the work accomplished by this LDRD ER (tracking number: 01-ERD-093). The main focus of the LDRD was on the research and development of an x-ray imaging instrument. The instrument design was based on a Wölter [1] Type-I design.

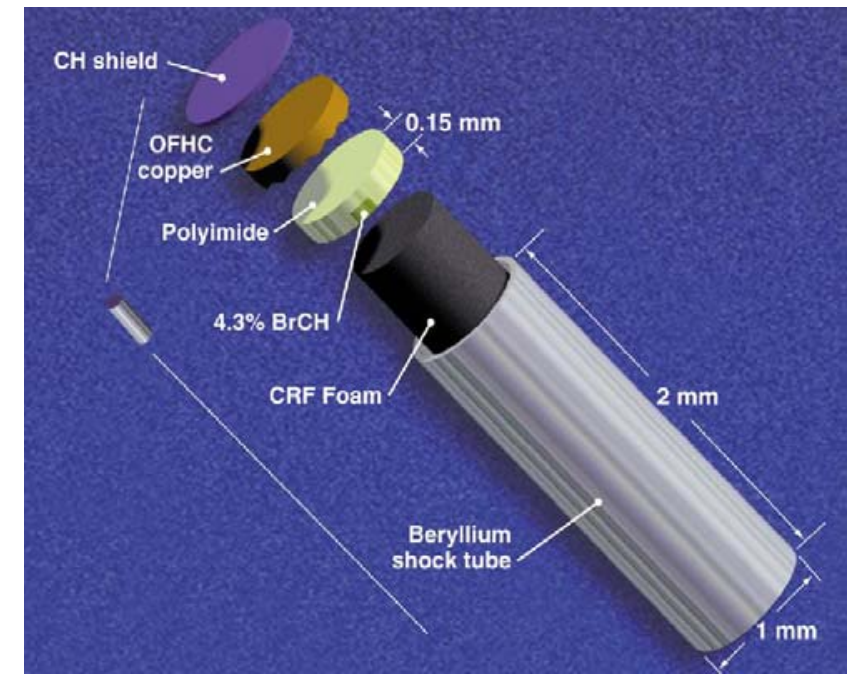

Figure 1.1: One possible configuration of a target assembly

The LDRD-ER began as a mid-year project in April 2001. After 2.5 years the LDRD-ER was combined with other work to create a new LDRD-SI. The LDRD-SI was terminated in December 2003. The x-ray microscope research and development was never completed. This report describes the work that was accomplished. It includes discussions on the instrument concept, the optical design, mandrel fabrication, instrument fabrication, optic fabrication, and optic testing. 


\subsection{The Wölter Instrument Concept}

The Wölter instrument uses two mirrors to focus x-rays that are exiting the target assembly. These $\mathrm{x}$-rays are focussed onto the image plane. The first mirror is hyperbolic and the second mirror is elliptical (see Figure 2.1). By using the configuration shown in Figure 2.1, x-rays that exit the center of the target (this is the right-sided hyperbolic focal point) will be imaged (without blur) at the center of the image plane (this is the right-sided elliptical focal point). X-rays that exit the target off-axis will be imaged at the image plane with a magnification and inverted. Moreover, off-axis points on the target will become blurred at the image plane. Since target assemblies do not release their own $\mathrm{x}$-rays, an $\mathrm{x}$-ray source is required. The $\mathrm{x}$-ray source is placed directly behind the target (see Figure 2.2).

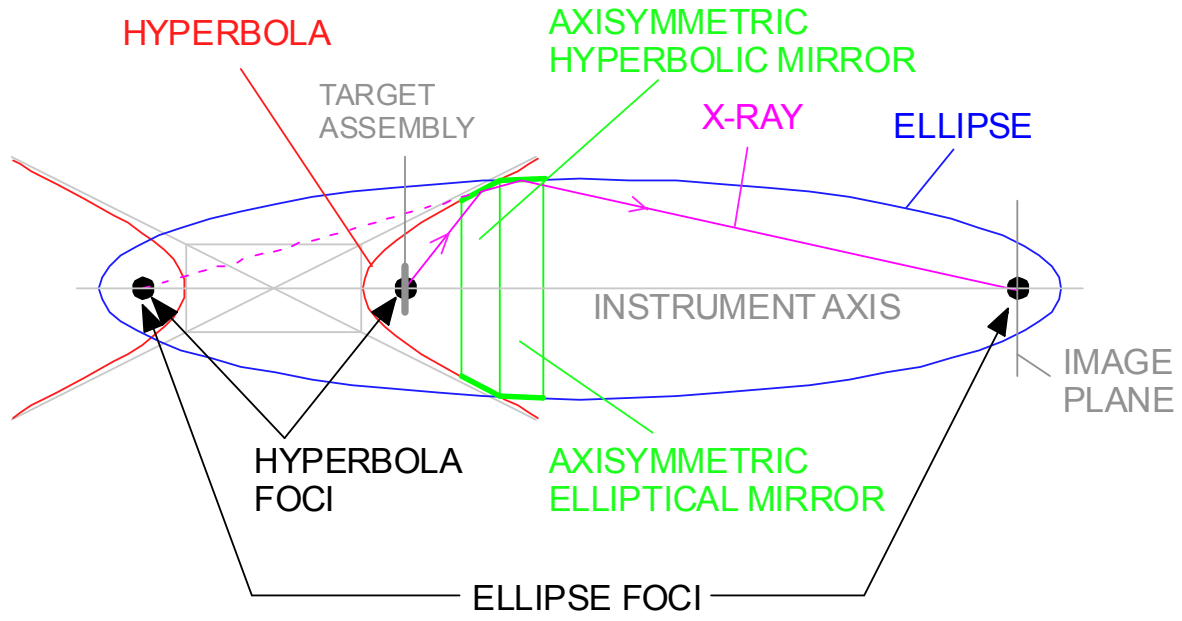

Figure 2.1: Wölter Geometry

The x-rays that strike the image plane need to be captured for image processing. This is accomplished by placing a scintillator at the image plane. The scintillator converts $\mathrm{x}$-ray photons into visible light. A CCD camera then captures this visible light. CCD cameras have fixed pixel sizes. The camera chosen has 9micrometer pixels. Hence, the CCD camera has a fixed resolution of 18 -micrometers because of aliasing problems associated with digital sampling. In order to achieve 0.5 -micrometer resolution at the target, we need to magnify the image by a minimum of 36 times $(0.5 \mathrm{um}$ x $36=18 \mathrm{um})$. The Wölter optics can be designed to do the entire magnification, or the magnification can be accomplished using a combination of Wölter optics and a lens system on the visible light side of the scintillator. It should be noted that the scintillator also has resolution limits. The scintillator resolution is approximately equal to its thickness. For example, a scintillator with 6-micrometer resolution should have a thickness no greater than 6micrometers. The conversion efficiency of a scintillator is also proportional to its thickness; hence, we do not want to make the scintillator too thin. Table 2.1 lists the magnification possibilities that we considered for the Wölter instrument. 


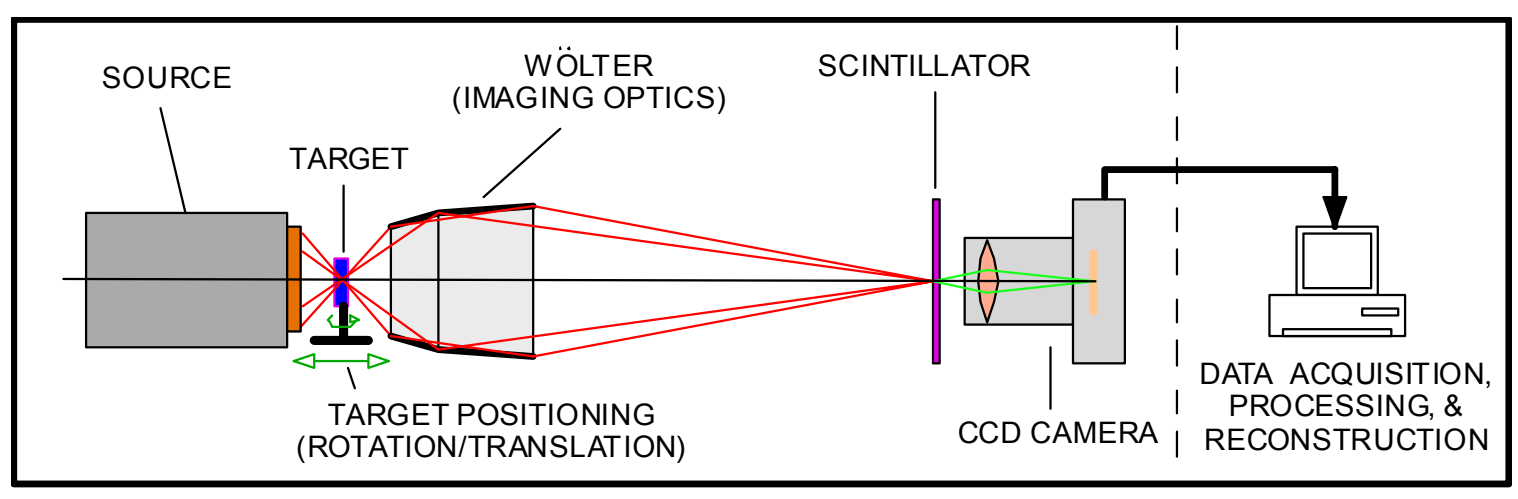

Figure 2.2: Illustration of a Wölter instrument that does not use condenser optics

\begin{tabular}{|l|l|l|l|l|l|}
\hline $\begin{array}{l}\text { Resolution at } \\
\text { the target }\end{array}$ & $\begin{array}{l}\text { Wölter } \\
\text { magnification }\end{array}$ & $\begin{array}{l}\text { Scintillator } \\
\text { resolution }\end{array}$ & $\begin{array}{l}\text { Optical } \\
\text { magnification }\end{array}$ & $\begin{array}{l}\text { CCD required } \\
\text { resolution }\end{array}$ & $\begin{array}{l}\text { CCD required } \\
\text { pixel size }\end{array}$ \\
\hline \multirow{5}{*}{$0.5 \mathrm{um}$} & $36 \mathrm{x}$ & $18 \mathrm{um}$ & $1 \mathrm{x}$ & & \\
\cline { 2 - 4 } & $18 \mathrm{x}$ & $9 \mathrm{um}$ & $2 \mathrm{x}$ & \multirow{4}{*}{18 um } & \multirow{3}{*}{$9 \mathrm{um}$} \\
\cline { 2 - 4 } & $12 \mathrm{x}$ & $6 \mathrm{um}$ & $3 \mathrm{x}$ & \\
\cline { 2 - 4 } & $9 \mathrm{x}$ & $4.5 \mathrm{um}$ & $4 \mathrm{x}$ & \\
\cline { 2 - 4 } & $6 \mathrm{x}$ & $3 \mathrm{um}$ & $6 \mathrm{x}$ & \\
\cline { 2 - 4 } & $3 \mathrm{x}$ & $1.5 \mathrm{um}$ & $12 \mathrm{x}$ & & \\
& & & & \\
\end{tabular}

Table 2.1: Magnification options

Our CCD camera has a 2000 pixel by 3000 pixel imaging chip. This results in a coverage of 0.5 -millimeter by 0.75 -millimeter $(2000 \times 9 \mathrm{um} / 36=0.50 \mathrm{~mm}$ and $3000 \times 9 \mathrm{um} / 36=0.75 \mathrm{~mm})$ at the target assembly. Since the targets are usually equal to or larger than 1 millimeter in length or diameter, we cannot obtain a radiograph of the entire target at one time with this CCD camera. In order to cover the entire target, we will need to take multiple images of different sections of the part and combine them into one image. This is commonly referred to as tiling (see Figure 2.3).

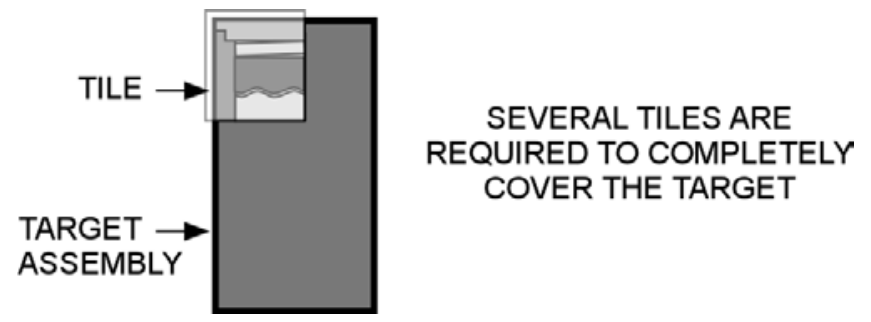

Figure 2.3: Several small radiographs tiled together can be used to create a complete target assembly radiograph 


\subsection{Optical Design}

Based on the design criteria of 1 micrometer resolution at the target, 36x magnification, large field of view, and high throughput, the following optical design parameters were chosen:

\begin{tabular}{|l|l|}
\hline Parameter Description & Value \\
\hline Use of condenser system & NO \\
\hline Wölter optics - magnification & $12 \mathrm{x}$ \\
\hline Visible magnification (between scintillator and CCD) & $3 \mathrm{x}$ \\
\hline Instrument length (object plane to image plane length) & 5 meters \\
\hline Maximum collection angle & 5.6 degrees \\
\hline Throughput (solid angle fraction, $1=$ full hemisphere) & $3 \times 10^{-4}$ \\
\hline
\end{tabular}

Figure 3.1 shows the expected blur versus field-of-view for this design. The design has a blur of almost 10micrometers at a 1-millimeter field-of-view. This is far from our original goal, but it still appears to be the most promising design. The details of the optical design can be found in UCRL-ID-150702 [2].

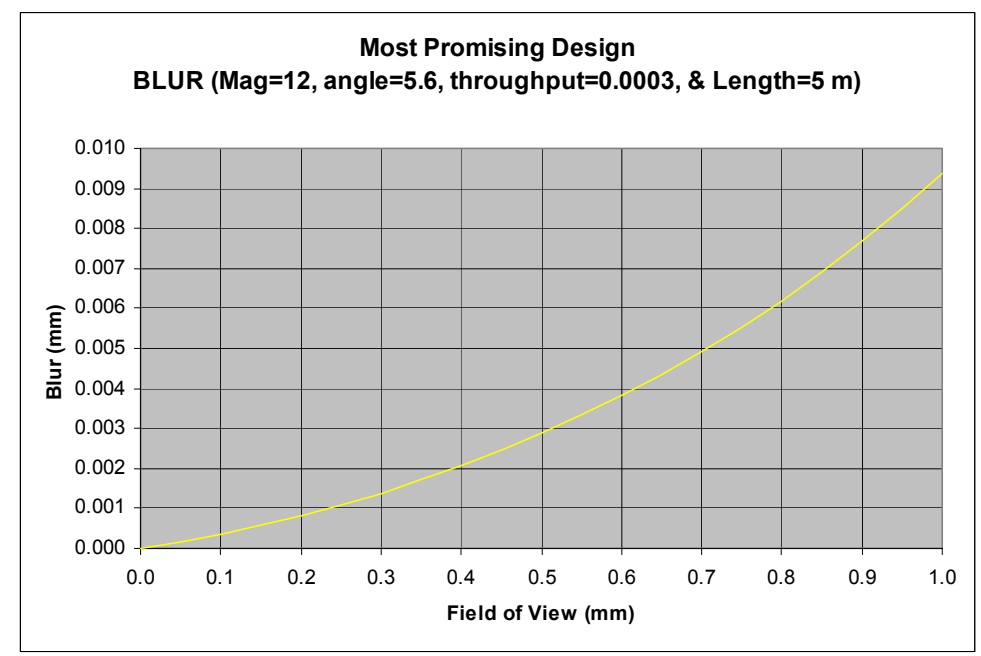

Figure 3.1: Blur versus field of view (diameter) for a promising design 


\subsection{Mandrel Fabrication}

The optic is essential to the success of the Wölter microscope. The optic requires a super-polished internal surface that uses multilayer coatings to enhance performance (see the optical design report [2] for more details on multilayers). Machining an optical shell and polishing the inside surface is extremely difficult. Moreover, applying multilayer coatings to a small-diameter (approximately 3 inches in our case) inside surface is nearly impossible. Therefore, we needed to use a different technique; we used a replication technique (Figure 4.1). Instead of making the optic directly, the optic was coated onto a mandrel and then separated from the mandrel. This allowed the polishing and multilayer application to be performed on an external face (the face of the mandrel).

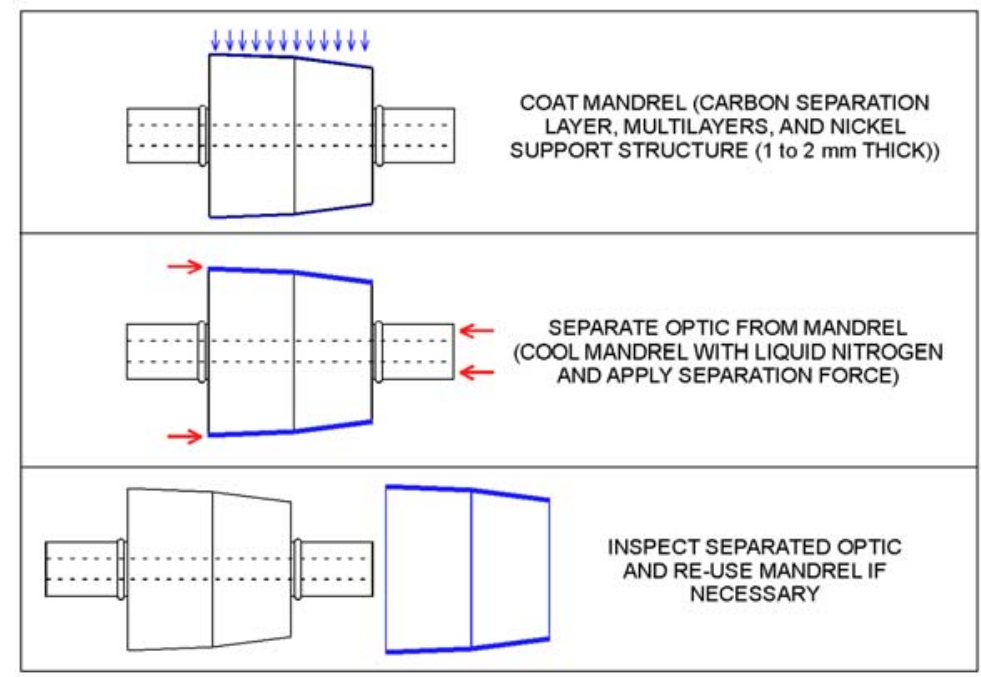

Figure 4.1: Optic fabrication process

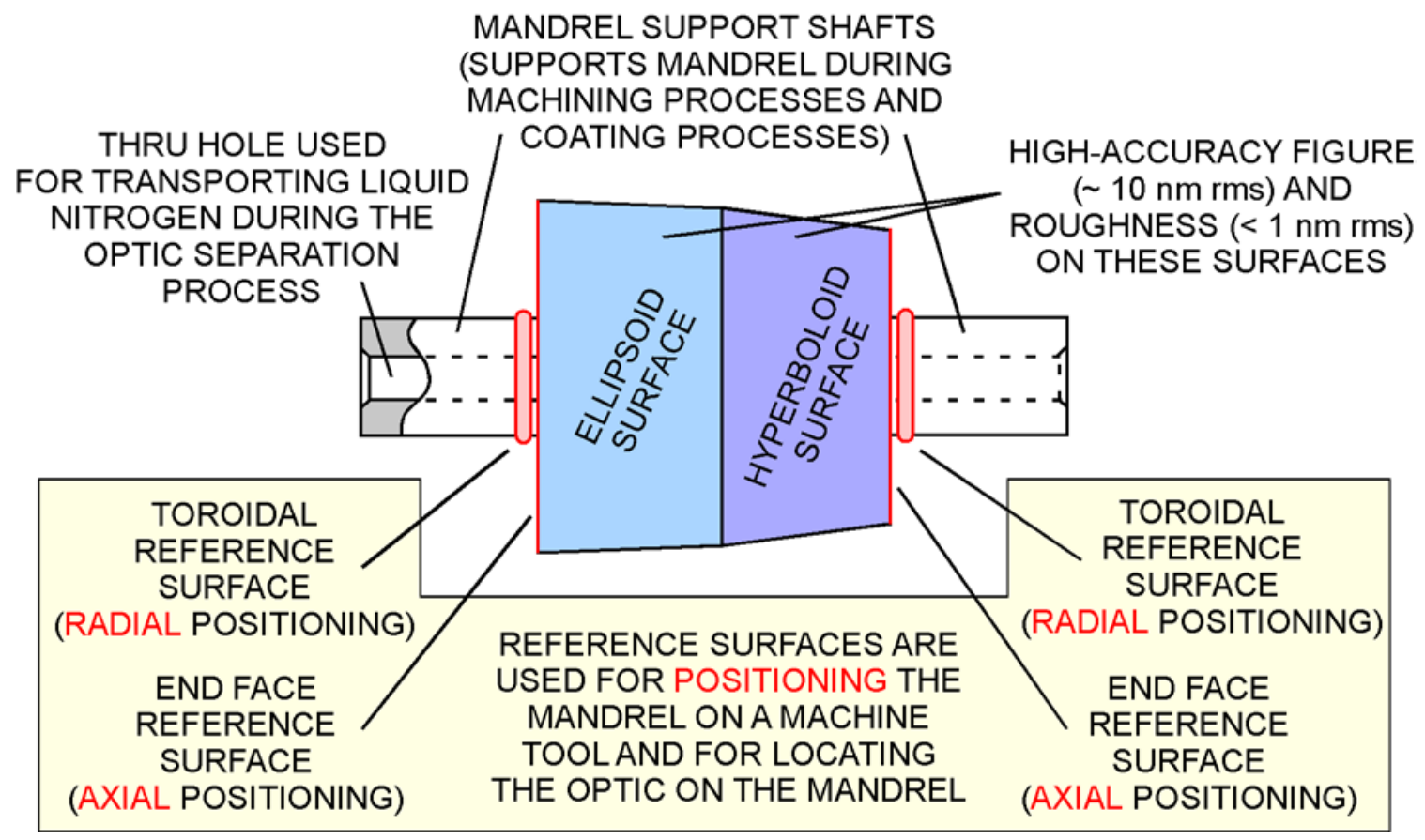

Figure 4.2: Mandrel Design 
Using the replication technique required the construction of a super-polished high-accuracy mandrel (see Figure 4.2) for fabricating the Wölter optic. Figure 4.3 shows the steps required to design and fabricate mandrels. More details about the mandrel fabrication process can be found in UCRL-JC-155073 [3]. Figure 4.4 shows a picture of our mandrel.



Figure 4.3: Fabrication process flowchart

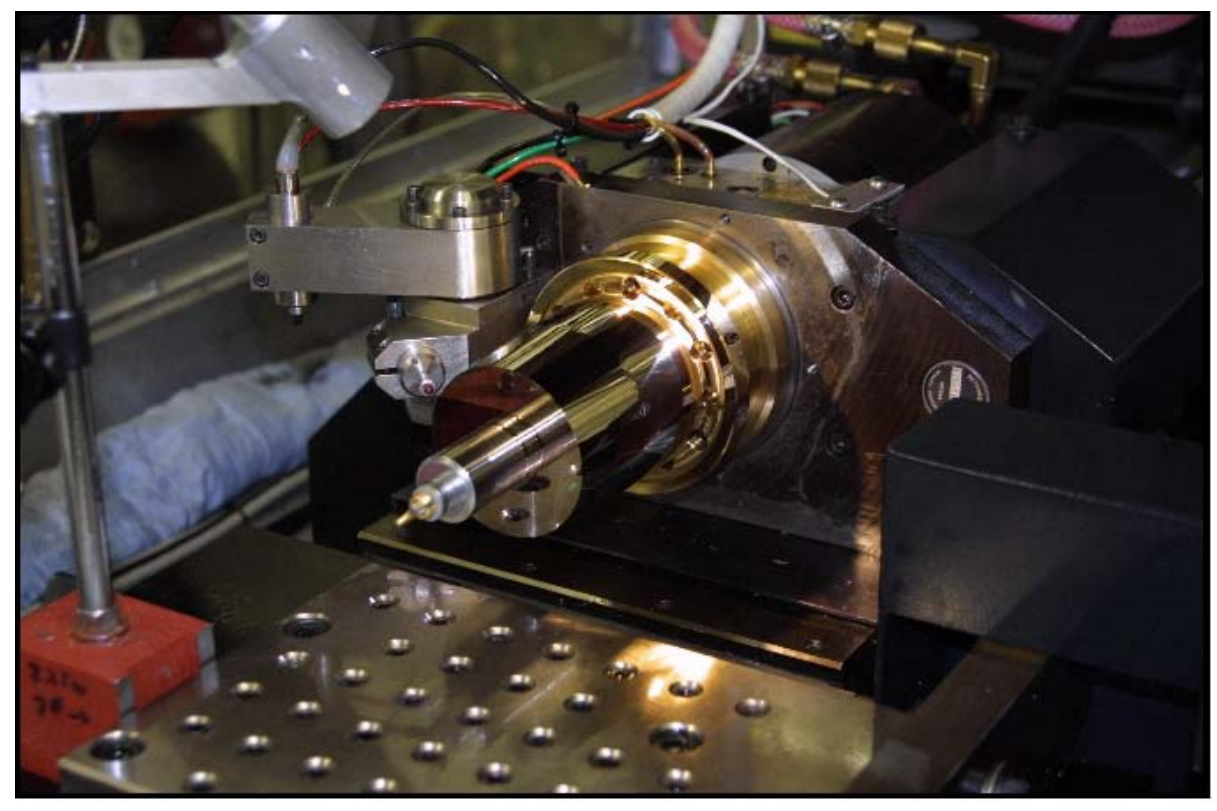

Figure 4.4: The mandrel on the diamond turning machine after completing the final cut. 


\subsection{Instrument Fabrication}

In order to achieve high-resolution imaging, the x-ray instrument needs to be thermally and vibrationally stable. Moreover, the design needs to hold all of the critical components accurately. Figure 5.1 shows a conceptual image of the instrument.

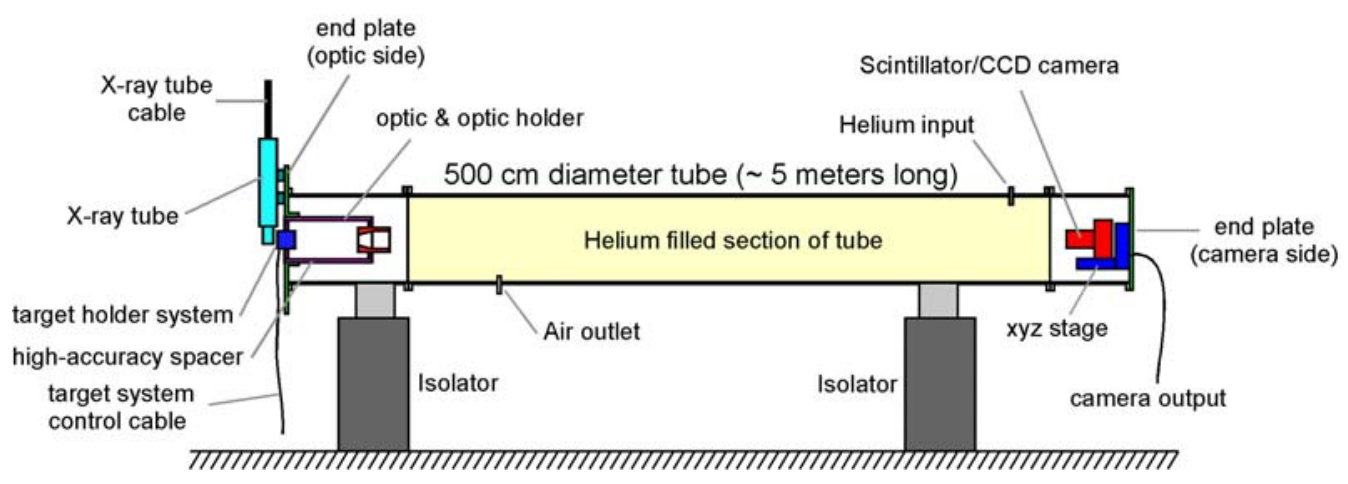

Figure 5.1: Conceptual image of the instrument

The target needed to be accurately positioned. A parallel mechanism was designed to accomplish this task. Figure 5.2a shows the mechanism concept. Figure 5.2b shows the detailed design of the mechanism. It uses flexures to accurately position the target.

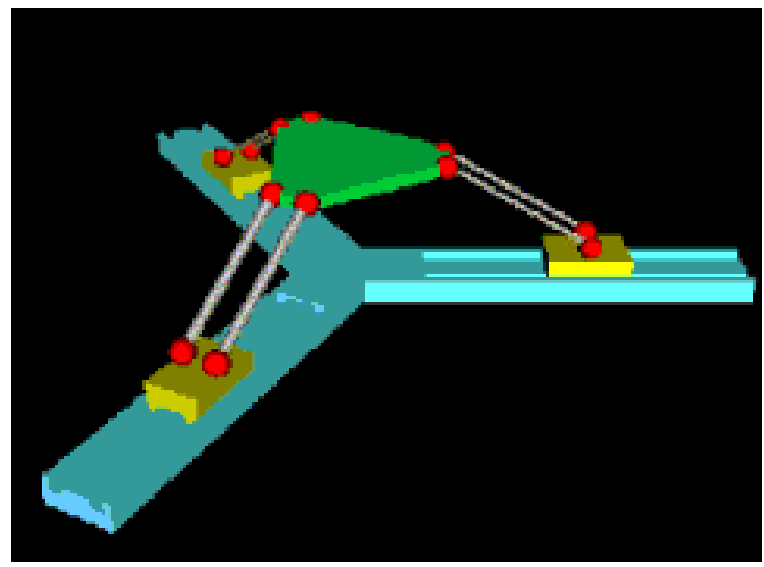

(a)

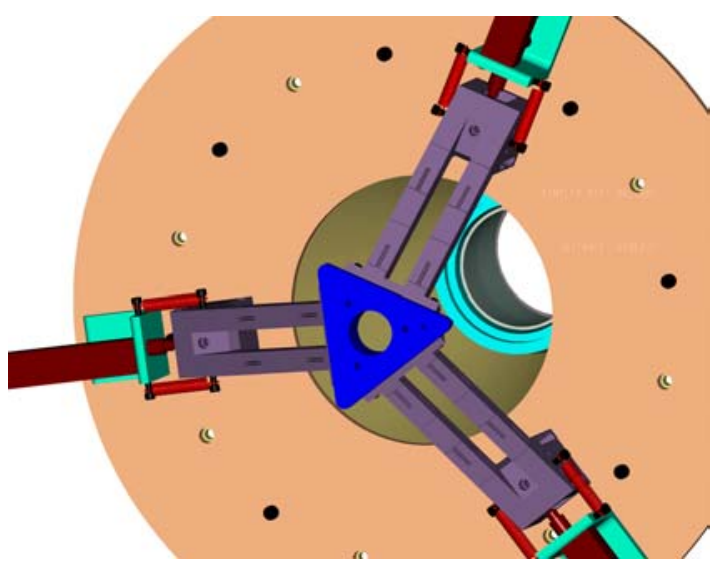

(b)

Figure 5.2: target positioning mechanism.

Figure 5.3 shows a CAD model of the instrument. The CAD model was completed and many of the parts were ordered and received. Figure 5.4 shows some of the parts. 


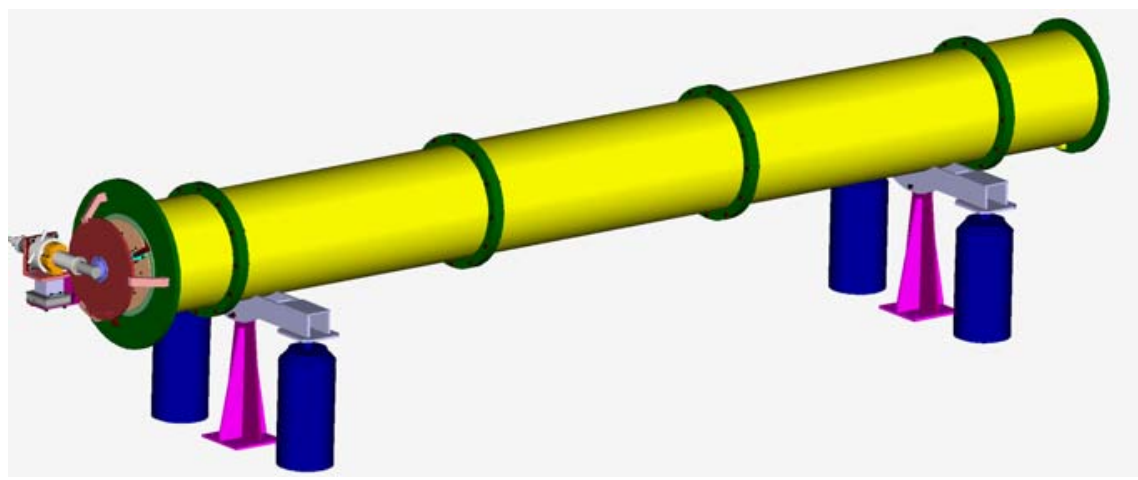

Figure 5.3: CAD model of the instrument

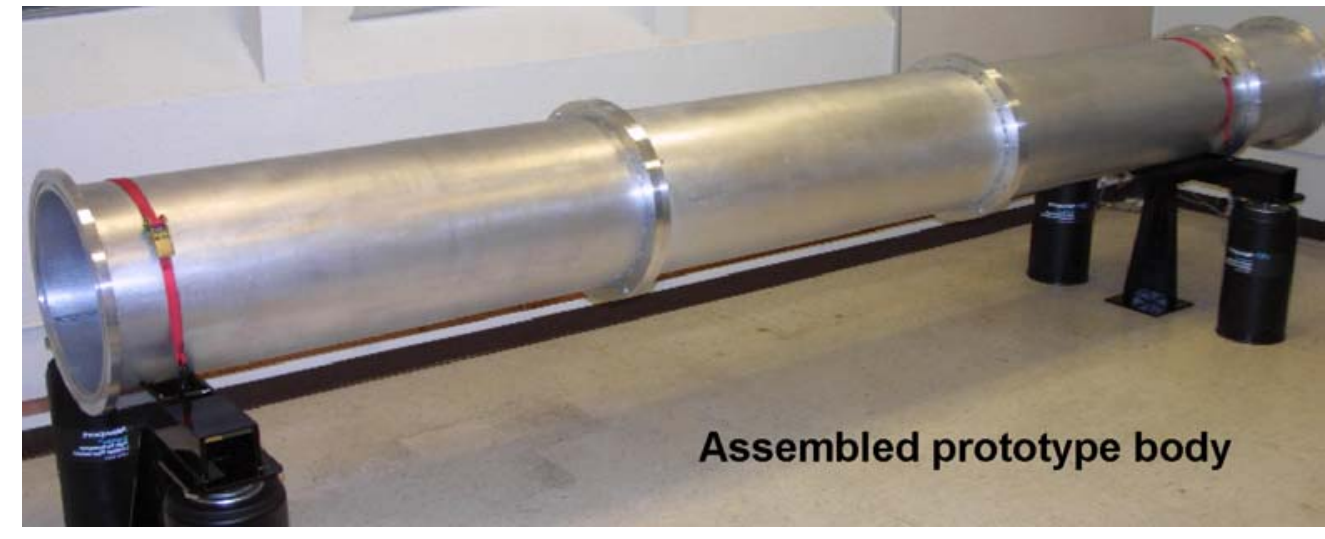

Figure 5.4: Partial assembly of the x-ray instrument prototype 


\subsection{Optic Fabrication}

After completing the polishing process, the mandrel was used to produce a high-fidelity replicated multilayer Wölter optic. An optic was created by applying many coatings and separating the coatings from the mandrel. Here are the steps that we used to produce the optic:

- Coat the mandrel with multilayers; this is done in a sputter deposition chamber (see Figure 6.1)

- Coat the mandrel with a thick (1 to 2 millimeters thick) layer of nickel to support the multilayers after separation

- Separate the coatings from the mandrel by applying a separation force to the coatings.

Each layer of a multilayer coating consists of a high-density (Tungsten carbide) sub-layer and a low-density (boron carbide) sub-layer. It is common to coat an optic with around 50 multilayers. As stated earlier, this is done in a sputter deposition chamber. The mandrel is rotated next to two sputter guns. One sputter gun applies Boron Carbide to the mandrel surface, and the other one applies tungsten carbide. The amount of material sputtered, the geometry of the system, and the mandrel rotation speed control the thickness of the layers. Since we wanted high-accuracy graded multilayers, fixtures were used to further control the amount of material applied from each sputter gun.

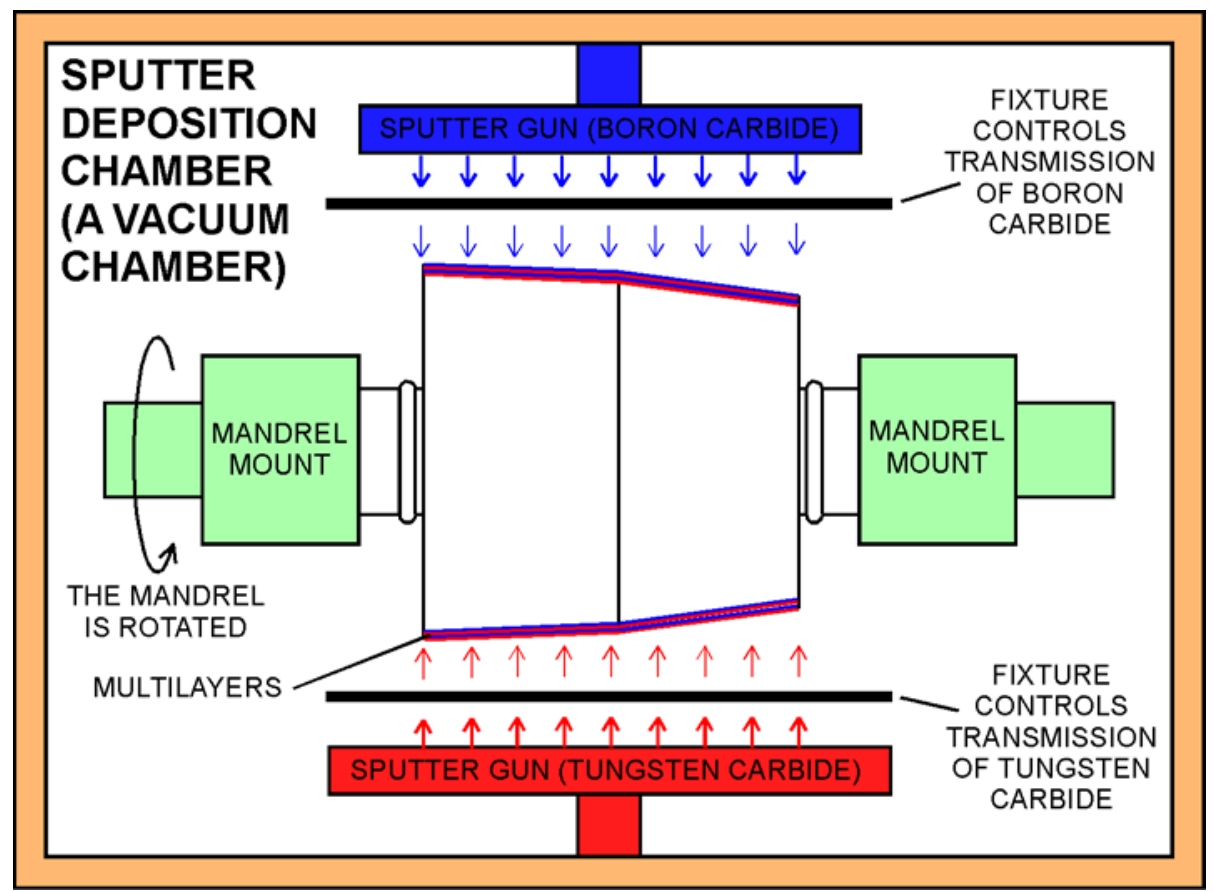

Figure 6.1: illustration of a sputter deposition chamber

Reflectivity measurements were needed in order to improve the multilayer deposition process. This was done using a test mandrel with flats to accommodate silicon wafers (see Figure 6.2). The multilayers were applied to the test mandrel - including the wafers. The wafers were removed and tested with an instrument that could measure the $\mathrm{x}$-ray reflection angle. After a few iterations, the multilayers were being applied as expected. 


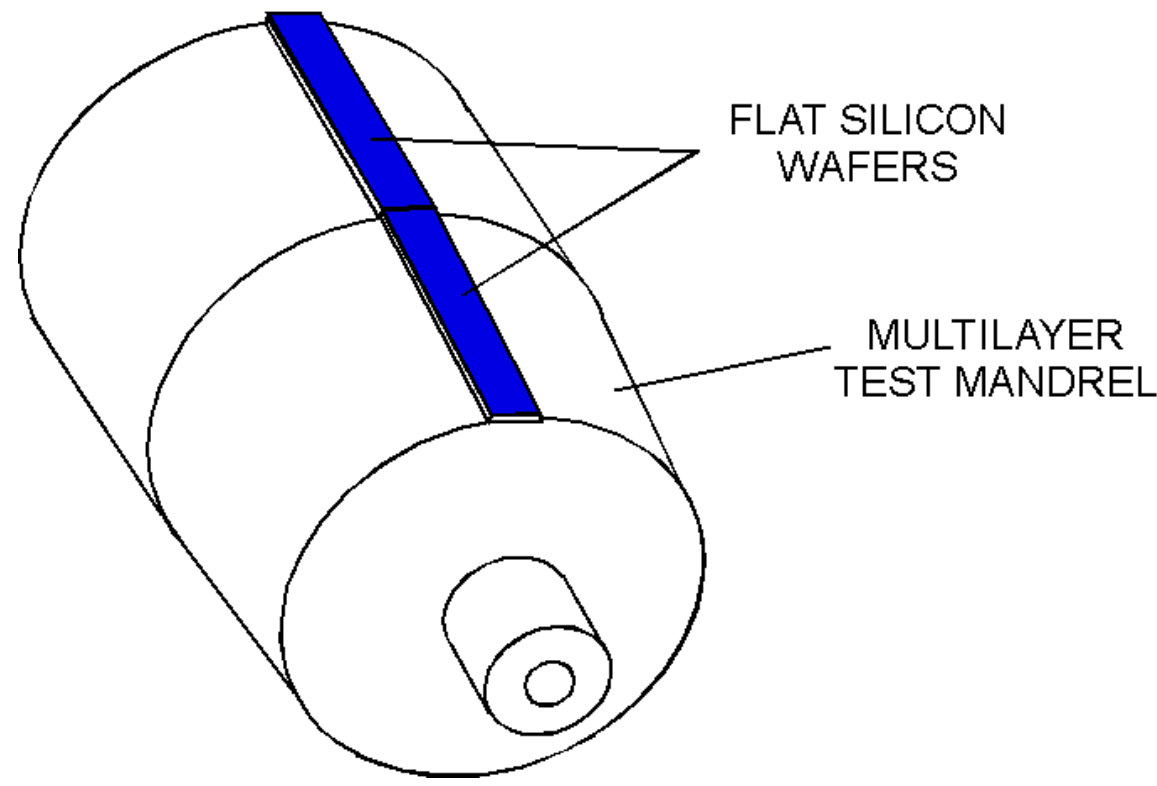

Figure 6.2: multilayer reflection test mandrel

After refining the multilayer application process, the super-polished mandrel was coated with multilayers and a thick layer of nickel. These coatings were then separated from the mandrel. After separating the optic from the mandrel, the nickel coating provided structural support for the reflective multilayer coatings. Figure 6.3 shows the final replicated test optic \& test mandrel.

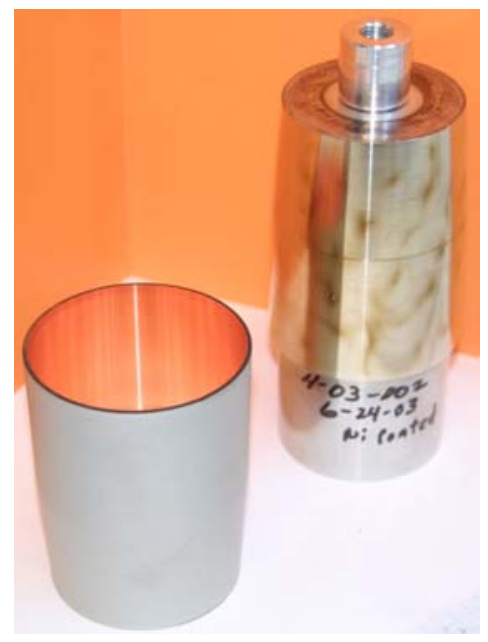

Figure 6.3: Replicated optic and its mandrel. 


\subsection{Optic Tests}

In December 2003, the replicated optic was brought to the Danish Space Research Institute (DSRI) in Copenhagen where it was tested using their $\mathrm{x}$-ray facility. At this time it was discovered that the replicated optic had poor performance due to mid-spatial frequency errors (form errors). Figure 7.1 shows the fixturing used to test the optic. Based on the knowledge obtained at DSRI, a new plan for creating better optics was formulated and an error analysis was created to show where improvements needed to be made.

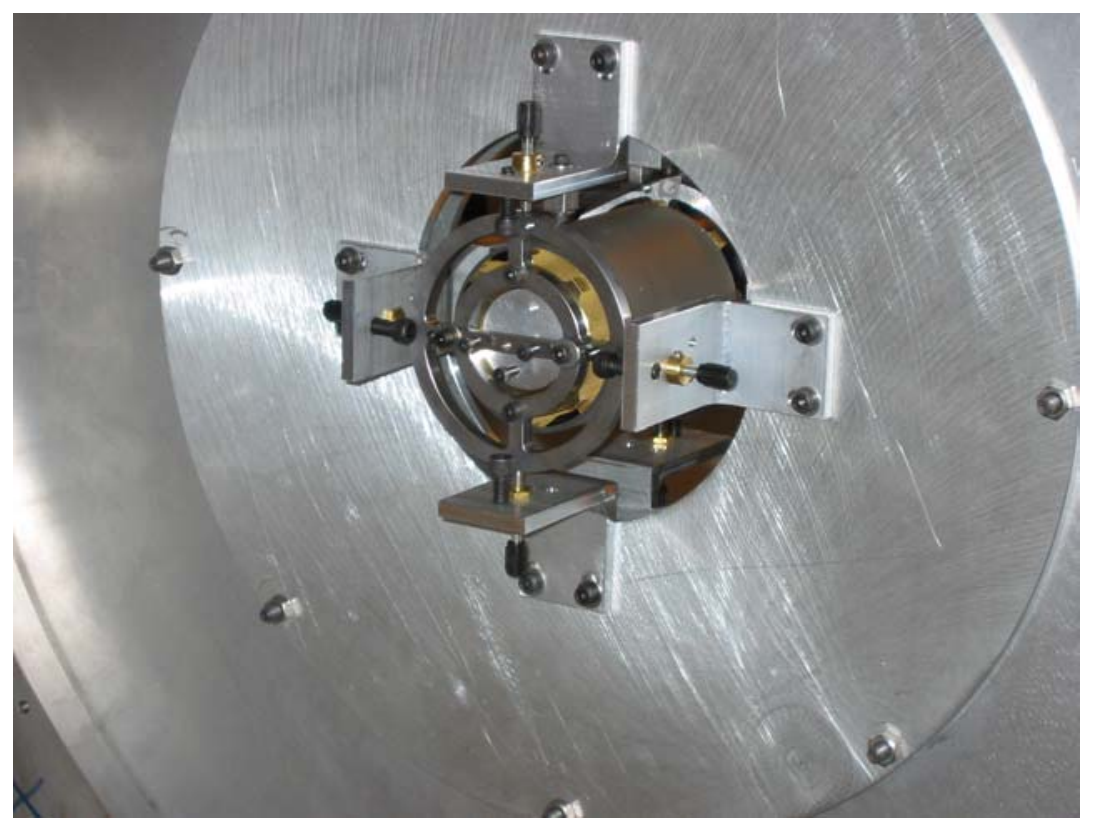

Figure 7.1: The optic and fixturing used to test the optic at DSRI

\subsection{Conclusion}

The LDRD was never completed. However, an optical design was created, a super-polished mandrel was made, a replicated $\mathrm{x}$-ray optic was fabricated, an instrument was designed, and an optic was tested. A lot was learned from this work. In the future, we should be able to produce much better replicated optics based on what was learned in this project.

\subsection{Bibliography}

1. Wölter, H., "Mirror Systems with Grazing Incidence as Image-Forming Optics for X-rays," Ann Physik, Vol. 10, 94, 1952.

2. W. W. Nederbragt, "Wolter Instrument - Optical Design,” October 11, 2002, UCRL-ID-150702.

3. W. W. Nederbragt, "Fabrication of a Precision Mandrel for Replicating Wolter X-ray optics," ASPE Annual Conference, Portland, OR, 2003, UCRL-JC-155073 
University of California

Lawrence Livermore National Laboratory

Technical Information Department

Livermore, CA 94551

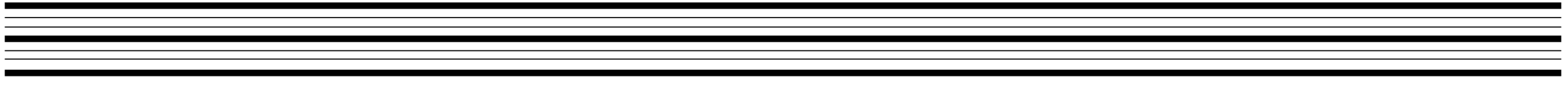

